\title{
Cell adherence-promoted activity of Plesiomonas shigelloides GroEL
}

\author{
Hitoshi Tsugawa, Humie Ito, Miho Ohshima and Yoshio Okawa \\ Department of Infection and Host Defense, Tohoku Pharmaceutical University, \\ 4-4-1 Komatsushima, Sendai Aoba-ku, Miyagi 981-8558, Japan
}

Correspondence

Yoshio Okawa

okawa@tohoku-pharm.ac.jp

Received 7 June 2006

Accepted 31 August 2006

\begin{abstract}
Previously, it has been demonstrated that the invasion of Caco-2 cells by Plesiomonas shigelloides induces apoptotic cell death. Therefore, the attachment to and colonization of eukaryotic intestinal host cells by $P$. shigelloides are important steps in causing pathogenicity. In this study, the participation of $P$. shigelloides GroEL in the attachment of $P$. shigelloides was examined. The groESL operon of $P$. shigelloides was isolated by PCR. The nucleotide sequence of the groESL operon of $P$. shigelloides revealed two ORFs of 294 nucleotides for groES and 1647 nucleotides for groEL. Cell fractionation and immunostaining experiments suggested that the GroEL of $P$. shigelloides was associated with the bacterial cell surface. The expression of the groEL gene was upregulated during the attachment and apoptosis-induction stages, and the expression of the protein was also induced during the attachment stage. Furthermore, GroEL efficiently promoted the attachment of $P$. shigelloides to Caco-2 cells, as measured by a FACSCalibur flow cytometer. These results demonstrated that GroEL has a positive influence on the attachment of $P$. shigelloides to Caco-2 cells.
\end{abstract}

\section{INTRODUCTION}

Plesiomonas shigelloides is recognized as a causative organism of diarrhoeal disease (Brenden et al., 1998; Saraswathi et al., 1983). Several potential and putative virulence factors that could play a role in the pathogenicity of $P$. shigelloides have been examined (Falcon et al., 2003; Janda \& Abbott, 1993; Okawa et al., 2004; Theodoropoulos et al., 2001). Recently, we have demonstrated the mechanism of invasion of $P$. shigelloides into Caco-2 cells and that the invasion of $P$. shigelloides induces apoptotic cell death (Tsugawa et al., 2005). These results show that an interaction between the bacteria and the host cells is important for the pathogenicity of $P$. shigelloides. Therefore, the analysis of factors which are involved in the interaction between P. shigelloides and host cells is important to understand the infection mechanism of the bacteria. In this study, we focused on P. shigelloides GroEL, known to be a chaperone or heat-shock protein (HSP).

HSPs have been grouped into families according to molecular mass, and members of each family have common features (Goulhen et al., 1998). Some HSPs function as chaperones, and may help in transporting proteins across cell membranes or in protein folding (Goulhen et al., 1998). The production of HSPs is greatly

Abbreviations: HSP, heat-shock protein; ICAM-1, intercellular adhesion molecule-1.

The GenBank/EMBL/DDBJ accession number for the groESL operon sequence of $P$. shigelloides is AB251936. enhanced by stress stimuli such as heat, acid or osmotic shock, and iron deprivation (Hennequin et al., 2001a; Retzlaff et al., 1994). The main function of HSPs is preservation of essential cellular proteins and their functions. HSPs are predominantly located in intracellular compartments, but recent studies suggest that some HSPs can be expressed on the bacterial surface and secreted extracellularly (Garduno et al., 1998a; Paju et al., 2000; Phadnis et al., 1996). Recent studies using immunocytochemical experiments have indicated that GroEL is involved in microbial pathogenicity: the $66 \mathrm{kDa} \mathrm{HSP}$ of Salmonella typhimurium, the GroEL of Haemophilus ducreyi, HSP60 of Legionella pneumophila and the GroEL of Clostridium difficile are involved in interactions between the bacteria and host cells (Ensgraber \& Loos, 1992; Frisk et al., 1998; Garduno et al., 1998b; Hennequin et al., 2001b). Furthermore, it has also been demonstrated that HSPs of Escherichia coli increase cytokine and adhesion molecule expression (Galdiero et al., 1997; Marcatili et al., 1997; Retzlaff et al., 1994).

Based on these experimental results, we have investigated the possibility that GroEL is involved in the initial stage (attachment) of $P$. shigelloides infection. First, we isolated and characterized the $P$. shigelloides groESL operon, and demonstrated the localization of the GroEL protein in the whole bacterial cell. Next, in order to understand the role of GroEL at the point of bacterial attachment, we examined the adhesion of the bacteria to Caco-2 cells stimulated with GroEL by using a flow cytometer. Finally, we showed that 


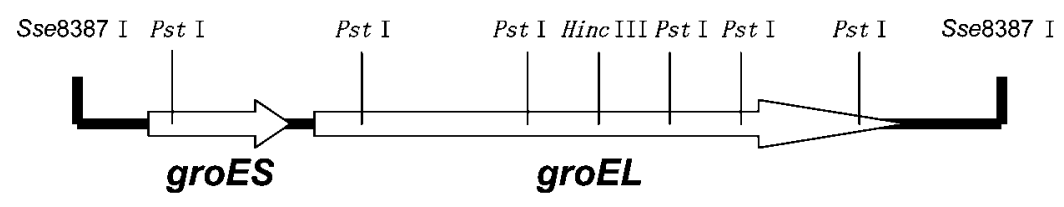

$400 \mathrm{bp}$

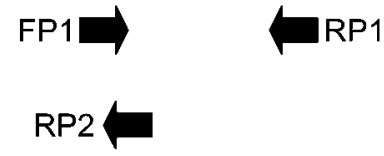

RP1
Fig. 1. Structure and cloning strategy of the $P$. shigelloides P-1 strain groESL operon. The Sse8387 I fragment of $P$. shigelloides genomic DNA, as shown by Southern blot analysis, was ligated into the Sse8387 I site of the pGEM-3Z vector. FP $1 / 2$ and RP1/2 denote the PCR primers; the combination of FP1 and RP1 was used for cloning the first fragment of groEL, RP2 and vector-specific primer SP6 for the upstream region of groEL, including groES and the promoter region, and FP2 and vector-specific primer SP6 for the downstream region of groEL.
Caco-2 cells stimulated with GroEL induced the expression of intercellular adhesion molecule-1 (ICAM-1).

\section{METHODS}

$\boldsymbol{P}$. shigelloides strains and growth conditions. The $P$. shigelloides P-1 strain used in this study was a clinical isolate from the Osaka Prefectural Institute of Public Health (Tsukamoto et al., 1978). The bacteria were grown in brain heart infusion (BHI) broth (Difco) for $18 \mathrm{~h}$ at $37^{\circ} \mathrm{C}$ with shaking.

DNA isolation and cloning of the $P$. shigelloides groESL operon. The bacterial cell pellets from $12 \mathrm{~h}$ culture were sonicated and centrifuged. The supernatant was loaded to Sephacryl S-100 $\mathrm{HR}$, and then subjected to antibody affinity chromatography. In order to determine the molecular mass and the $\mathrm{N}$-terminal amino acid sequence, the fraction containing GroEL was separated on SDSPAGE and transferred to a PVDF membrane (Problott, Applied Biosystems). The N-terminal amino acid sequence of the blotted protein was determined by Edman degradation. It was identified that the purified protein was a GroEL from the $\mathrm{N}$-terminal amino acid sequence. The genomic DNA of $P$. shigelloides was extracted using a Wizard Genomic DNA Purification kit (Promega). The groESL operon of $P$. shigelloides was amplified by PCR in three different fragments using three sets of primers that included FP1/2 and $\mathrm{RP} 1 / 2$ (Fig. 1). Primers used in the PCR reactions are shown in Table 1. The first set of primers, FP1 and RP1, was designed based on the P. shigelloides GroEL N-terminal amino acids (AAKDVKFG) and the GroEL motif sequence, respectively. For $50 \mu \mathrm{l}$ of the PCR reaction, $10 \mathrm{ng} P$. shigelloides genomic DNA was used. Thermal cycling conditions were initial denaturation at $94^{\circ} \mathrm{C}$ for $5 \mathrm{~min}$, followed by 35 cycles at $94^{\circ} \mathrm{C}$ for $30 \mathrm{~s}, 63^{\circ} \mathrm{C}$ for $30 \mathrm{~s}$ and $72{ }^{\circ} \mathrm{C}$ for $1.5 \mathrm{~min}$, and a final extension at $72{ }^{\circ} \mathrm{C}$ for 5 min using Ex Taq DNA polymerase (TaKaRa). The PCR products $(600 \mathrm{bp})$ were purified by a QIAquick gel extraction kit (Qiagen). The purified PCR products were directly sequenced by a CEQ DTCS Quick Start kit (Beckman Coulter) and an automatic DNA sequencer (CEQ8000XL, Beckman Coulter). In the next step, using the first PCR products (600 bp) as a probe, genomic Southern blot analysis of the chromosomal DNA, which had been digested with Sse8387 I, was performed. The Sse8387 I fragment shown by Southern blot analysis was ligated into the Sse8387 I site of the pGEM-3Z Vector (Promega) and transformed into Escherichia coli DH5 $\alpha$ (TaKaRa). The second fragment was PCR-amplified from the plasmid DNA using the vector-specific primer SP6 and RP2 (based on the sequence determined for the first fragment). Finally, the third fragment was PCR-amplified from the plasmid DNA using the vector-specific primer SP6 and FP2 (based on the GroEL motif sequence). The second (560 bp) and third (900 bp) fragments were cloned into the pCR4-TOPO vector and transformed into TOP10 chemically competent E. coli cells
(Invitrogen). The plasmid DNAs were purified using a Wizard Plus SV Minipreps DNA purification system (Promega), and the inserts were sequenced using the same conditions as mentioned for the first fragments. The sequences of all three fragments of the $P$. shigelloides groESL operon were combined and aligned using Genetyx version 7 (Software Development). The complete groESL operon of P. shigelloides was PCR-amplified and cloned into the pCR4-TOPO vector. The sequence of the groESL operon and the deduced amino acid sequence were analysed using Genetyx version 7 .

Protein expression and purification of the $\boldsymbol{P}$. shigelloides GroEL. Two oligonucleotide primers, Ex-FP and Ex-RP, incorporating NdeI and SpeI sites in pET-41a $(+)$, respectively, shown in Table 1 (lower-case italic type), were synthesized and used to PCRamplify the full-length coding region of the groEL of $P$. shigelloides. The PCR products (1600 bp) were cloned into the pCR4-TOPO vector and transformed into TOP10 chemically competent $E$. coli cells (Invitrogen). The plasmid DNA was purified and digested with NdeI and SpeI, and the inserts were cloned into pET-4la $(+)$, which had been digested with NdeI and SpeI, and transformed into E. coli

Table 1. Primers used in PCR reactions

\begin{tabular}{|ll|}
\hline Primer & \multicolumn{1}{c|}{ Primer sequence $\left(\mathbf{5}^{\prime} \rightarrow \mathbf{3}^{\prime}\right)$} \\
\hline Cloning primers & \\
FP1 & GCAGCTAAAGACGTAAAATTCGG \\
RP1 & GGCTTGTTGATGAAGTAAGGAGA \\
FP2 & ACTACGGTTACAACGCAGC \\
RP2 & CTACGTTACGGCCTTTTGGACC \\
Expression primers & \\
Ex-FP & catatgGCAGCTAAAGACG \\
Ex-RP & actagtTACATCATGCCGCC \\
One-step RT-PCR & \\
primers & \\
P. shigelloides-16S & GTTTGATCATGGCTCAGATTGAAC \\
rRNA FP & \\
P. shigelloides-16S & TTACCTTGTTACGACTTCACCCC \\
rRNA RP & \\
P. shigelloides-groEL FP & ATGGCAGCTAAAGACGTAAAATTCG \\
P. shigelloides-groEL RP & TTACATCATGCCGCCCA \\
Caco-2 Actin FP & TACGCCAACACAGTGCTGTCT \\
Caco-2 Actin RP & TACTCCGCTTGCTGATCCACAT \\
Caco-2 ICAM-1 FP & CATGCAGCACCTCCTGTGAC \\
Caco-2 ICAM-1 RP & AGGGAGGCGTGGCTTGTG \\
& \\
\hline
\end{tabular}


BL21 (DE3) (Novagen). The transformed bacteria were cultured in Luria-Bertani broth (Invitrogen) supplemented with kanamycin $\left(30 \mu \mathrm{g} \mathrm{ml}^{-1}\right)$, and expression of the GroEL was induced with $1 \mathrm{mM}$ IPTG at $37^{\circ} \mathrm{C}$. The bacterial cells were harvested by centrifugation and lysed by a BugBuster HT (Novagen). Inclusion bodies were harvested and washed three times with RIPA buffer $[25 \mathrm{mM}$ Tris/ $\mathrm{HCl}$ $(\mathrm{pH} 7.5), 150 \mathrm{mM} \mathrm{NaCl}, 0.1 \%(\mathrm{w} / \mathrm{v})$ SDS, $1 \%(\mathrm{v} / \mathrm{v})$ Triton X-100, $1 \%(\mathrm{w} / \mathrm{v})$ deoxycholic acid]. Inclusion bodies were solubilized in $10 \%(\mathrm{w} / \mathrm{v})$ SDS, and then refolded by dialysis.

Anti-GroEL antibody production. A rabbit polyclonal, monospecific GroEL antiserum was prepared. Purified protein $(300 \mu \mathrm{g})$ was injected together with Freund's complete adjuvant (Difco) into Japanese White rabbits (SLC), followed by boosters with $300 \mu \mathrm{g}$ protein in Freund's complete adjuvant at days 7, 21 and 28. The rabbits were killed and bled 14 days after the last injection. The antiserum was pooled and stored at $-20^{\circ} \mathrm{C}$ until use.

Western immunoblot. The protein concentration in the samples was determined by a BCA Protein Assay Reagent kit (Pierce) using BSA as a standard. SDS-PAGE was done using the PhastSystem (Amersham Bioscience) with a 10-15\% gradient PhastGel. Western immunoblotting was performed as described previously by Okawa et al. (2004), using rabbit antisera against the P. shigelloides GroEL protein $(1: 1000$ dilution). Following $1 \mathrm{~h}$ incubation with this first antibody, the nitrocellulose membrane was washed three times with PBS. The nitrocellulose membrane was then reacted with goat antirabbit antibody coupled to horseradish peroxidase (1:1000 dilution; Biosource) for $1 \mathrm{~h}$, and the membrane was washed three times with PBS and then developed with the 3,3'-diaminobenzidine (DAB) colour development reagent. The intensity of GroEL signals was analysed by densitometric scanning of the membranes using a gel video system (GelDoc EQ, Bio-Rad) and image analysis software (Quantity One, Bio-Rad).

Fractionation of bacterial cells. Fractionation was performed as previously described by Goulhen et al. (1998). Bacterial cells were exposed to osmotic shock with ice-cold distilled water for $10 \mathrm{~min}$, the suspension was centrifuged, and the supernatant contained the periplasmic material. The pellet was sonicated, centrifuged at $6000 \mathrm{~g}$ for $15 \mathrm{~min}$, and the supernatant was centrifuged at $200000 \mathrm{~g}$ for $2 \mathrm{~h}$. The resulting supernatant was dialysed against distilled water and contained the cytoplasmic material. The pellet was resuspended in $2 \%(\mathrm{v} / \mathrm{v})$ Triton $\mathrm{X}-100$ containing $10 \mathrm{mM} \mathrm{MgCl} 2$. The latter suspension was centrifuged at $200000 \mathrm{~g}$ for $1 \mathrm{~h}$. The supernatant contained the cytoplasmic-membrane-rich cell envelope, and the pellet resuspended in distilled water contained the outer-membranerich cell envelope. All fractions were kept at $-20^{\circ} \mathrm{C}$ prior to further analysis.

Stress cultivations. Heat shock was induced in the stationary phase of growth by transferring cultures grown at $37^{\circ} \mathrm{C}$ to a $43^{\circ} \mathrm{C}$ water bath and incubating for $60 \mathrm{~min}$. To investigate the effect of iron starvation, bacteria were cultured at $37^{\circ} \mathrm{C}$ in iron-limited medium prepared by adding $200 \mu \mathrm{M} 2,2^{\prime}$-dipyridyl (Nacalai tesque) to BHI medium. To investigate the effect of osmolarity, bacteria were cultivated at $37^{\circ} \mathrm{C}$ in $\mathrm{BHI}$ medium containing $150 \mathrm{mM} \mathrm{NaCl}$.

RT-PCR analysis of gene expression during infection. The RNA of $P$. shigelloides during Caco-2 cell infection was extracted using an SV Total RNA Isolation system (Promega). The resulting RNAs of $P$. shigelloides at different stages during Caco- 2 cell infection were amplified using the specific primers listed in Table 1. The $P$. shigelloides 16S rRNA gene (Martinez-Murcia et al., 1992) was used as the internal control for RT-PCR.

The RT-PCR reaction was carried out with the SuperScript III OneStep RT-PCR system with Platinum Taq High Fidelity (Invitrogen), in a $50 \mu \mathrm{l}$ mixture containing $1 \mu \mathrm{g}$ RNA template, $0.5 \mu \mathrm{M}$ of the primers (a)

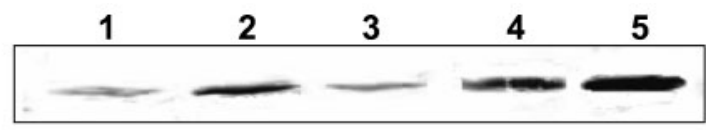

(b)

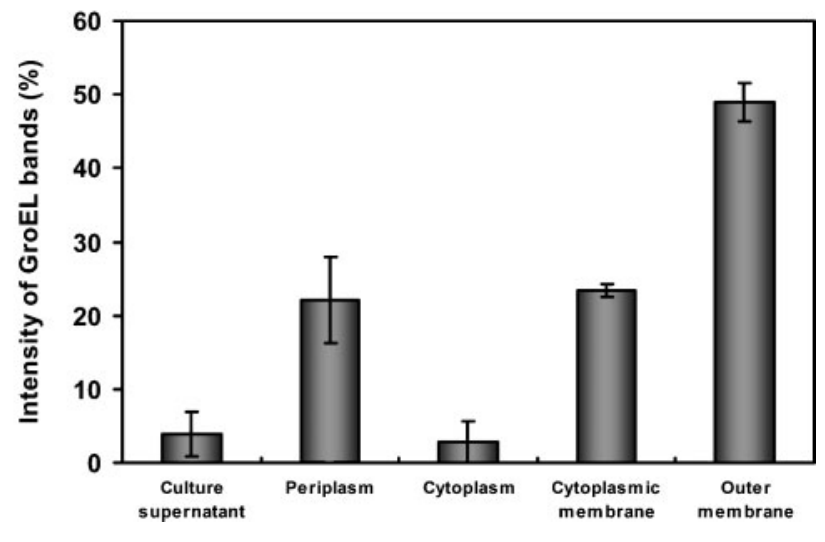

Fig. 2. Presence of the GroEL protein in various cell fractions of $P$. shigelloides $\mathrm{P}-1$ strain. (a) Western immunoblotting detection of the GroEL protein in fractions of $P$. shigelloides $P$ 1. Each lane contained $0.4 \mu \mathrm{g}$ protein. Lanes: 1, culture supernatant; 2, periplasm; 3, cytoplasm; 4, cytoplasmic membrane; 5, outer membrane. (b) Densitometric analysis of GroEL. The GroEL bands were quantified by the densitometry function of the Quantity One software. Results are means \pm SD of three independent assays.

P. shigelloides-groEL FP and P. shigelloides-groEL RP (Table 1), and $2 \times$ Reaction Mix, with a reaction mixture formulated according to the manufacturer's instructions. The cDNA synthesis step was performed at $55^{\circ} \mathrm{C}$ for $30 \mathrm{~min}$ and a predenaturation step at $94{ }^{\circ} \mathrm{C}$ for $2 \mathrm{~min}$, followed by 60 cycles at $94^{\circ} \mathrm{C}$ for $15 \mathrm{~s}, 54^{\circ} \mathrm{C}$ for $30 \mathrm{~s}$ and $68^{\circ} \mathrm{C}$ for $3 \mathrm{~min}$, and a final extension at $68^{\circ} \mathrm{C}$ for $5 \mathrm{~min}$. The amounts of $\mathrm{groEL}$ product were analysed by densitometric scanning of gels using a gel video system (GelDoc EQ) and image analysis software (Quantity One).

Adherence promotion by GroEL. Measurement of Caco-2 cells with $P$. shigelloides attached was conducted using a FACSCalibur flow cytometer (Becton Dickinson). Direct flow cytometry was done using $P$. shigelloides labelled with FITC (Sigma). The labelling of $P$. shigelloides with FITC was carried out by the method of Tsugawa et al. (2005) as follows. P. shigelloides was suspended in $500 \mu \mathrm{l}$ PBS

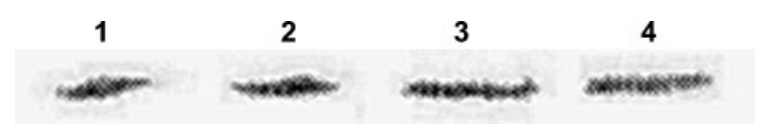

Fig. 3. Effect of several stresses on synthesis of $P$. shige/loides GroEL. Western immunoblot analysis is shown of GroEL present in total protein extracts of $P$. shigelloides detected with antibodies against GroEL. Lanes: 1, normal conditions; 2, heat treatment $\left(43^{\circ} \mathrm{C}\right)$ for 60 min of normally cultured cells; 3 , irondeprived conditions; 4, elevated osmolarity conditions. Each lane contained proteins from equivalent numbers of bacteria. 


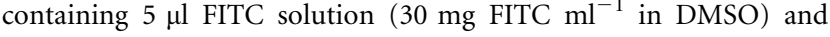
incubated at room temperature for $2 \mathrm{~h}$. The labelled bacteria were washed eight times in PBS and suspended in $500 \mu \mathrm{l}$ PBS. The Caco2 cells were seeded at a density of $10^{6}$ per well in a 24-well tissueculture plate and incubated for $18 \mathrm{~h}$ in Dulbecco's Modified Eagle's Medium (DMEM; Gibco) with $10 \%$ (v/v) fetal bovine serum (FBS) at $37^{\circ} \mathrm{C}$ in $5 \% \mathrm{CO}_{2}$. The labelled bacteria $\left(5.0 \times 10^{8}\right)$ were added to each well containing a monolayer of Caco-2 cells, and the mixture was incubated at $37^{\circ} \mathrm{C}$ in $5 \% \mathrm{CO}_{2}$ for $10 \mathrm{~min}$. The monolayer was washed three times with PBS, and the fluorescence intensity of the cells was then measured by the FACSCalibur flow cytometer.

An adherence-promoting assay for GroEL was conducted using the purified GroEL protein and a FACSCalibur flow cytometer as follows. First, the monolayer of Caco-2 cells was incubated with 10, 20 and $30 \mu \mathrm{g}$ of GroEL or BSA (control) in DMEM with $10 \%$ (v/v) FBS for 60 min at $37^{\circ} \mathrm{C}$ under a $5 \% \mathrm{CO}_{2}$ atmosphere. After that, the FITClabelled bacteria $\left(5.0 \times 10^{8}\right)$ were infected for $10 \mathrm{~min}$. The monolayer was washed three times with PBS and the fluorescence intensity of the cells was then measured by a FACSCalibur flow cytometer. Analysis of the data was performed using the CELLQuest software program (Becton Dickinson). The assays were repeated three times.

Expression of ICAM-1 on Caco-2 cells stimulated with GroEL. The expression of ICAM-1 on Caco- 2 cells which had been incubated with GroEL for $60 \mathrm{~min}$ at $37^{\circ} \mathrm{C}$ in $5 \% \mathrm{CO}_{2}$ was evaluated by two different methods. (i) RT-PCR analysis of ICAM-1 gene expression, and (ii) flow cytometer studies that used mouse antihuman ICAM-1 conjugated with FITC (Biosource) to determine ICAM-1 expression on the cell surface.

For the RT-PCR analysis of ICAM-1 gene expression, the RNA of the Caco- 2 cells which had been incubated with GroEL or BSA (control) for $60 \mathrm{~min}$ at $37^{\circ} \mathrm{C}$ in $5 \% \mathrm{CO}_{2}$ with 10,20 and $30 \mu \mathrm{g}$ of protein were extracted using an SV Total RNA isolation system. The resulting RNAs of Caco-2 cells stimulated with GroEL or BSA were amplified using the specific primers listed in Table 1. The RT-PCR reaction was carried out with the SuperScript III One-Step RT-PCR system with Platinum Taq High Fidelity, in a $50 \mu \mathrm{l}$ mixture containing $1 \mu \mathrm{g}$ RNA template, $0.5 \mu \mathrm{M}$ of the primers Caco-2 ICAM-1 FP and Caco-2 ICAM-1 RP (Table 1), and $2 \times$ Reaction Mix, with a reaction mixture formulated according to the manufacturer's instructions. The cDNA synthesis step was performed at $55^{\circ} \mathrm{C}$ for $30 \mathrm{~min}$, and a predenaturation step at $94{ }^{\circ} \mathrm{C}$ for $2 \mathrm{~min}$, followed by 40 cycles at $94^{\circ} \mathrm{C}$ for $15 \mathrm{~s}, 57^{\circ} \mathrm{C}$ for $30 \mathrm{~s}$ and $68^{\circ} \mathrm{C}$ for $3 \mathrm{~min}$, and a final extension of $68^{\circ} \mathrm{C}$ for $5 \mathrm{~min}$. For the Caco$2 \beta$-actin, the Caco- 2 Actin FP and Caco- 2 Actin RP primers shown in Table 1 were used as the internal control for RT-PCR (Wang et al., 2000).

For the flow cytometry, $30 \mu \mathrm{g}$ GroEL or $30 \mu \mathrm{g}$ BSA (control) were added to each well containing the monolayer of Caco- 2 cells, and incubated at $37^{\circ} \mathrm{C}$ in $5 \% \mathrm{CO}_{2}$ for $60 \mathrm{~min}$. The monolayer was washed three times with PBS, followed by $1 \mathrm{~h}$ incubation with mouse antihuman ICAM-1 conjugated with FITC (1:100 DMEM dilutions). The monolayer was washed three times with PBS, and the fluorescence intensity of the cells was then measured by a FACSCalibur flow cytometer. Analysis of the data was performed using CELLQuest software. Each experiment was repeated four times.

\section{RESULTS AND DISCUSSION}

\section{Molecular cloning and sequence analysis of the groESL operon of $\boldsymbol{P}$. shigelloides}

The GroEL protein of the P. shigelloides P-1 strain was purified as described in Methods. The molecular mass of the (a)

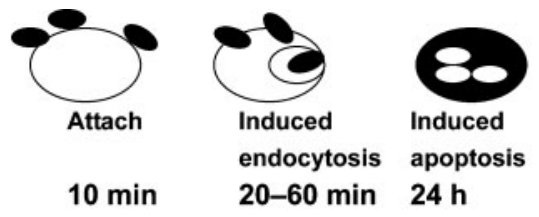

Time post infection

(b)

1507 bp

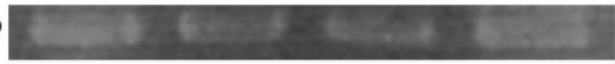

16S rRNA

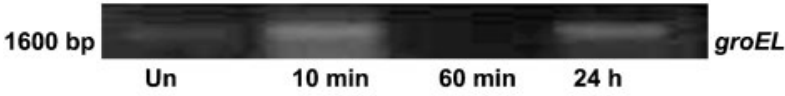

(c)

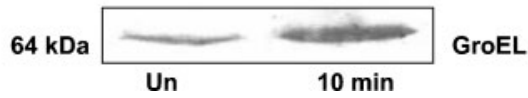

Fig. 4. Kinetics of GroEL expression during in vitro $P$. shige/loides $\mathrm{P}-1$ strain infection. (a) Various stages during $P$. shige/loides infection, such as attachment, internalization and apoptosis induction. (b) The transcription of groEL in Caco-2 cells at various stages during $P$. shigelloides infection was determined by one-step RT-PCR. Amplified products were electrophoresed on $0.8 \%$ agarose gels stained with ethidium bromide. The $P$. shigelloides $16 \mathrm{~S}$ rRNA was used as an endogenous control to confirm an equivalent quantity of template loading. The size of the amplified fragment is indicated on the left. Un, RNA isolated from bacteria that had not been in contact with Caco-2 cells; $10 \mathrm{~min}, 60 \mathrm{~min}$ and $24 \mathrm{~h}$, RNA isolated from bacteria that had been in contact with Caco-2 cells. (c) Western immunoblotting detection of GroEL in P. shigelloidesinfected Caco-2 cells at the attachment stage during $P$. shige/loides infection. Un, proteins isolated from bacteria that had not been in contact with Caco-2 cells; 10 min, proteins isolated from bacteria that had been in contact with Caco-2 cells. Each lane contained proteins from equivalent numbers of bacteria. Data were from a representative experiment repeated three times.

GroEL was $64 \mathrm{kDa}$ from the results of SDS-PAGE and Western immunoblotting (data not shown). We determined that the N-terminal sequence of the GroEL was AAKDVKFGNDARVKMLXXVNV ( $\mathrm{X}$ is an unidentified amino acid) by automatic Edman degradation. The groESL operon of the $P$. shigelloides $\mathrm{P}-1$ strain was cloned and sequenced as described in Methods. We cloned a $2.7 \mathrm{~kb}$ DNA fragment containing the groESL operon of $P$. shigelloides by PCR in three different fragments (Fig. 1). The nucleotide sequence of the groESL operon of $P$. shigelloides has been submitted to GenBank under accession number AB251936. The sequence analysis of the groESL operon (2292 bp) of $P$. shigelloides revealed two ORFs of 294 nucleotides (97 amino acids) for groES and 1647 nucleotides (548 amino acids) for groEL. Only groES was preceded by a potential promoter sequence, -35 
(a)

GroEL

$10 \mu \mathrm{g}$

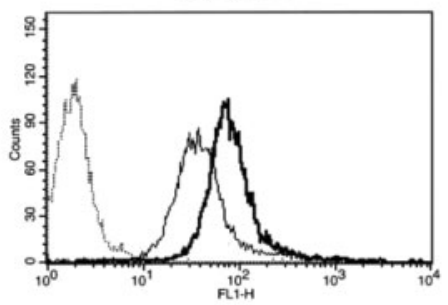

$20 \mu \mathrm{g}$

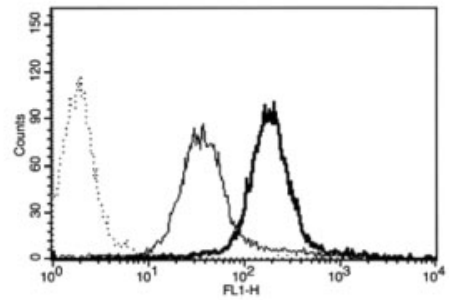

$30 \mu \mathrm{g}$

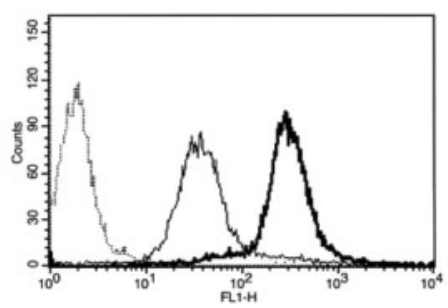

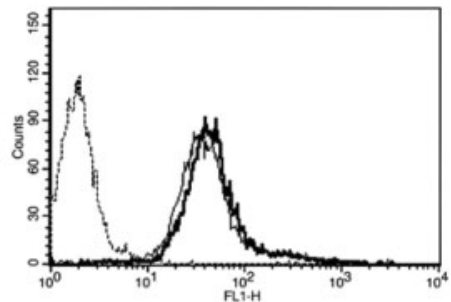

(b)

BSA
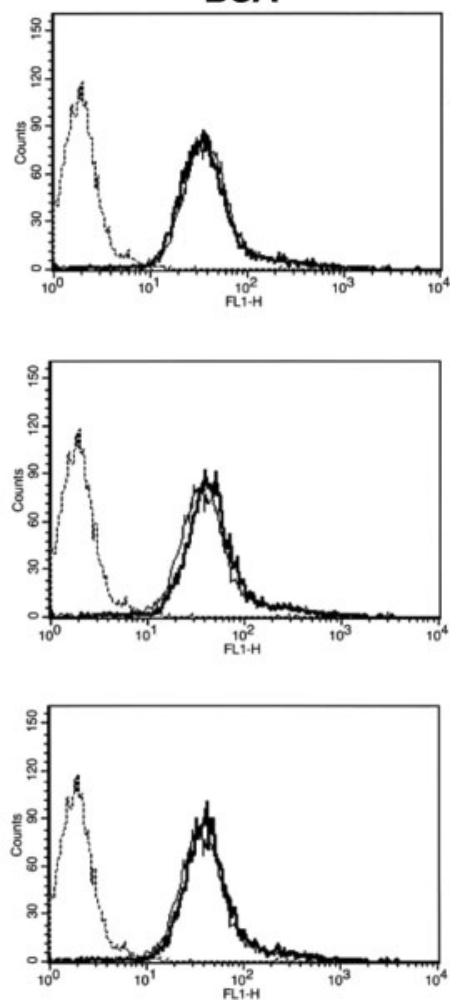

Fig. 5. Representative patterns of the effect of GroEL on attachment promotion using a flow cytometer. Dotted lines, control Caco-2 cells alone; solid lines, Caco-2 cells infected with FITC-labelled $P$. shigelloides for $10 \mathrm{~min}$; bold lines, Caco-2 cells pretreated with 10,20 and $30 \mu \mathrm{g}$ of GroEL (a) or BSA (b), which were added to the cells for 60 min prior to the addition of FITC-labelled $P$. shigelloides. The amounts of GroEL and BSA are indicated at the left. Data were from a representative experiment repeated three times.
(TTGAAT) and -10 (TATCAT) (data not shown). Compared with other chaperonins, the putative $P$. shigelloides GroEL protein displayed 99 and $98 \%$ identity to those of E. coli and Salmonella typhimurium, respectively. The putative $P$. shigelloides GroES protein exhibited 100 and $90 \%$ identity, respectively, to E. coli and S. typhimurium homologues.

\section{Localization of and effect of several stresses upon GroEL}

P. shigelloides P-1 strain was fractionated as described in Methods. The proteins in each fraction were separated by SDS-PAGE and analysed for GroEL proteins by Western immunoblotting (Fig. 2a), and the band intensity of GroEL protein by Western immunoblotting was quantified using the densitometry function of the Quantity One software (Fig. 2b). GroEL protein was found in culture supernatant and in both the soluble (cytoplasmic and periplasmic) and membrane fractions (Fig. 2a). The GroEL protein was detected principally in the outer-membrane, secondly in the periplasm and cytoplasmic membrane, and thirdly in the culture supernatant and cytoplasm (Fig. 2a, b). The amount of detected GroEL protein in the outer membrane was about twice that in the periplasm and cytoplasmic membrane, and it was about 12 times that in the culture supernatant and cytoplasm (Fig. 2b). The results obtained by fractionation of the bacterial cells were further corroborated by indirect immunostaining investigations of whole bacteria, using the
anti-GroEL antibody and preimmune serum. The former yielded strong colouring under stress cultivation (high osmolarity medium), whereas the preimmune serum did not react with these cells (data not shown).

The production of $P$. shigelloides GroEL was induced by cultivation under stresses such as heat, iron deprivation and osmotic shock (Fig. 3). The surface association of GroEL was also induced by stress cultivation (osmotic shock) (data not shown).

How the GroEL of $P$. shigelloides ends up on the bacterial surface is unclear, since the protein does not carry a classical signal peptide. The GroEL of $P$. shigelloides was secreted in the culture supernatant after 4 h cultivation, as measured by ELISA and Western immunoblotting (data not shown). Therefore, it can be assumed that the protein is released by autolysis, or secreted by type III or IV secretion machinery, or by a simple system such as an ABC transporter in the extracellular space, and is then absorbed on adjacent bacteria.

\section{Kinetics of groEL expression during in vitro $P$. shigelloides infection}

Next in this study we characterized the $P$. shigelloides groEL transcriptional profiles during $P$. shigelloides infection of Caco- 2 cells. RT-PCR was performed on synthesized cDNA from samples collected during specific stages of the $P$. shigelloides infection, such as attachment, internalization 
(a)

\begin{tabular}{|c|c|c|c|c|c|c|}
\hline & \multicolumn{3}{|c|}{ BSA stimulated } & \multicolumn{3}{|c|}{ GroteL stimulated } \\
\hline & $10 \mu \mathrm{g}$ & $20 \mu \mathrm{g}$ & $30 \mu \mathrm{g}$ & $10 \mu \mathrm{g}$ & $20 \mu \mathrm{g}$ & $30 \mu \mathrm{g}$ \\
\hline -Actin & 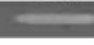 & 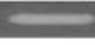 & 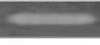 & 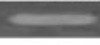 & 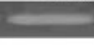 & $=$ \\
\hline
\end{tabular}

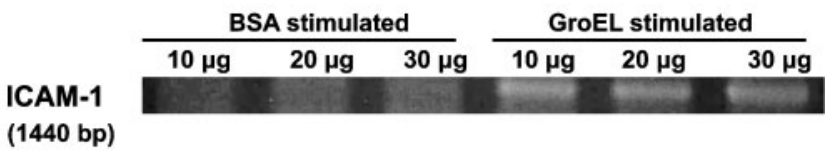

(b)

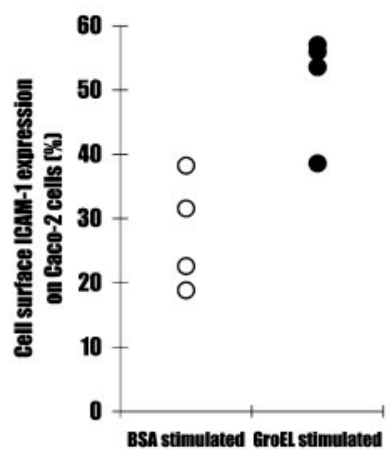

Fig. 6. RT-PCR and flow-cytometric analysis of ICAM-1 expressed by GroEL-stimulated Caco-2 cells. (a) The transcription of ICAM-1 in Caco-2 cells stimulated with 10, 20 and $30 \mu \mathrm{g}$ GroEL or BSA was determined by one-step RT-PCR. Amplified products were electrophoresed on $0.8 \%$ agarose gels stained with ethidium bromide. The $\beta$-actin of Caco- 2 cells was used as an endogenous control to confirm an equivalent quantity of template loading. The size of the amplified fragment is indicated on the left. (b) The ICAM-1 expression of the Caco-2 cell surface stimulated with $30 \mu \mathrm{g}$ GroEL or BSA was determined by flow-cytometric analysis. Data were from a representative experiment repeated three times.

and apoptosis induction (shown diagrammatically in Fig. 4a). When the samples were assayed for expression of the $P$. shigelloides $16 \mathrm{~S}$ rRNA gene, amplification was observed for all samples, confirming that $P$. shigelloides RNA was present in sufficient quantity and quality to allow detection (Fig. 4b). Expression of groEL was upregulated at two points: during the attachment stage and the apoptosisinduction stage. After attachment, during the internalization stages, the groEL transcriptional level decreased (Fig. 4b). Densitometric scanning of the upregulated amplified products revealed a two-threefold increase in GroEL expression in comparison with uninfected Caco-2 cells (Un). By Western immunoblotting, the expression of GroEL protein was also induced during the attachment stage (Fig. 4c).

We speculate that host-cell contact could send a signal to $P$. shigelloides, the result of which is increased expression of GroEL followed by the induction of the surface association of GroEL. There is therefore a possibility that GroEL is involved in P. shigelloides infection, for example during the attachment and apoptosis-induction stages.

\section{GroEL plays a role in cell attachment and ICAM-1 induction}

Next we examined the role of GroEL at the attachment stage. Because chaperone proteins of the GroEL family have an essential function in bacteria, we did not attempt to inactivate the groEL gene. Consequently, the Caco-2 cells were incubated with 10,20 and $30 \mu \mathrm{g}$ of GroEL or BSA (control) for $60 \mathrm{~min}$. After that, they were infected with FITC-labelled $P$. shigelloides for $10 \mathrm{~min}$ and the fluorescence intensity of the cells was then measured by a FACSCalibur flow cytometer. The mean fluorescence intensities of Caco-2 cells uninfected (Fig. 5, dotted lines) and infected with FITC-labelled P. shigelloides for $10 \mathrm{~min}$ (Fig. 5, solid lines) were 2.23 and 49.85, respectively. An increase in fluorescence intensity was caused by the adhesion of the bacteria (Tsugawa et al., 2005). Furthermore, the mean fluorescence intensities of Caco-2 cells pretreated with 10, 20 and $30 \mu \mathrm{g}$ GroEL were 73.81, 150.93 and 231.64, respectively, and this was related to GroEL in a dose-dependent manner (Fig. 5a, bold lines). On the other hand, the mean fluorescence intensities of Caco-2 cells pretreated with 10,20 and $30 \mu \mathrm{g}$ BSA were 49.23, 50.07 and 53.89, respectively, and in comparison with GroEL, these changed little with the different doses (Fig. 5b, bold line). These results showed that the adhesion of the bacteria to the Caco-2 cells was stimulated efficiently by GroEL.

How does GroEL of $P$. shigelloides promote the attachment of organisms to the Caco-2 cells? Two hypotheses can be proposed. First, the reactivity of the cell is altered by GroEL to promote the attachment of $P$. shigelloides, for example by the overexpression of a receptor involved in attachment. In this paper, we focused on ICAM- 1 and examined whether GroEL of $P$. shigelloides was able to increase the cell surface expression of ICAM-1. In fact, the expression of the ICAM-1 gene was upregulated in the Caco-2 cells stimulated with GroEL (Fig. 6a). Furthermore, as detected by the FACSCalibur flow cytometer, stimulation with $30 \mu \mathrm{g}$ GroEL increased the fluorescence intensity, which was shown by the expression level of ICAM-1 on the Caco- 2 cell surface. It was found that the fluorescence intensity of Caco2 cells was increased by the GroEL stimulus 1.8 times in comparison with the BSA (control) stimulus (Fig. 6b). These results showed that stimulation with GroEL increased the cellular mRNA levels of ICAM-1, and that as a result the expression of ICAM-1 on the Caco-2 cell surface was upregulated. The adhesion molecule ICAM-1 has been characterized as present in the Caco-2 human intestinal epithelial cell line and identified as a rhinovirus receptor (Kaiserlian et al., 1991). Recent studies have indicated that Haemophilus influenzae adheres to Chinese hamster ovary (CHO) cells by binding of P5 fimbriae to ICAM-1 (Avadhanula et al., 2006). However, we did not observe that the attachment promoted with GroEL was completely inhibited with anti-human ICAM-1 antibody, and the percentage inhibition was about $13 \%$, based on the decrease of the fluorescence intensity of the adhesion assay using a 
FACSCalibur flow cytometer (data not shown). Thus, this hypothesis does not appear to be valid for P. shigelloides.

As a second hypothesis, it is possible that GroEL binds to a Caco-2 cell surface protein after secretion and then interacts with a bacterial cell surface protein, forming a bridge between $P$. shigelloides and the Caco-2 cells, as described for Vibrio cholerae GbpA protein (Kirn et al., 2005). This hypothesis is supported by the fact that the GroEL was detected both in the culture supernatant and at the bacterial cell surface (Fig. 2). We will have to examine this hypothesis.

In conclusion, we demonstrated that the expression of $P$. shigelloides GroEL is induced by contact with host cells, and that the surface association of GroEL is also induced. The GroEL of $P$. shigelloides efficiently promoted the attachment of the bacteria, which is an important function for establishing infection.

\section{REFERENCES}

Avadhanula, V., Rodriguez, C. A., Ulett, G. C., Bakaletz, L. O. \& Adderson, E. E. (2006). Nontypeable Haemophilus influenzae adheres to intercellular adhesion molecule 1 (ICAM-1) on respiratory epithelial cells and upregulates ICAM-1 expression. Infect Immun 74, 830-838.

Brenden, R. A., Miller, M. A. \& Janda, J. M. (1998). Clinical disease spectrum and pathogenic factors associated with Plesiomonas shigelloides infections in humans. Rev Infect Dis 10, 303-316.

Ensgraber, M. \& Loos, M. (1992). A 66-kilodalton heat shock protein of Salmonella typhimurium is responsible for binding of the bacterium to intestinal mucus. Infect Immun 60, 3072-3078.

Falcon, R., Carbonell, G. V., Figueredo, P. M. S., Butiao, F., Saridakis, H. O., Pelayo, J. S. \& Yano, T. (2003). Intracellular vacuolation induced by culture filtrates of Plesiomonas shigelloides isolated from environmental sources. J Appl Microbiol 95, 273-278.

Frisk, A., Ison, C. A. \& Lagergard, T. (1998). GroEL heat shock protein of Haemophilus ducreyi: association with cell surface and capacity to bind to eukaryotic cells. Infect Immun 66, 1252-1257.

Galdiero, M., Delero, G. C. \& Marcatili, A. (1997). Cytokine and adhesion molecule expression in human monocytes and endothelial cells stimulated with bacterial heat shock proteins. Infect Immun 65, 699-707.

Garduno, R. A., Faulkner, G., Trevors, M. A., Vats, N. \& Hoffman, P. S. (1998a). Immunolocalization of Hsp60 in Legionella pneumophila. J Bacteriol 180, 505-513.

Garduno, R. A., Garduno, E. \& Hoffman, P. S. (1998b). Surfaceassociated Hsp60 chaperonin of Legionella pneumophila mediates invasion in a HeLa cell model. Infect Immun 66, 4602-4610.

Goulhen, F., Hafezi, A., Uitto, V. J., Hinode, D., Nakamura, R., Grenier, D. \& Mayrand, D. (1998). Subcellular localization and cytotoxic activity of the GroEL-like protein isolated from Actinobacillus actinomycetemcomitans. Infect Immun 66, 5307-5313.
Hennequin, C., Collignon, A. \& Karjalainen, T. (2001a). Analysis of expression of GroEL (Hsp60) of Clostridium difficile in response to stress. Microb Pathog 31, 255-260.

Hennequin, C., Porcheray, F., Waligora-Dupriet, A. J., Collignon, A., Barc, M. C., Bourlioux, P. \& Karjalainen, T. (2001b). GroEL (Hsp60) of Clostridium difficile is involved in cell adherence. Microbiology 147, 87-96.

Janda, J. M. \& Abbott, S. L. (1993). Expression of hemolytic activity by Plesiomonas shigelloides. J Clin Microbiol 31, 1206-1208.

Kaiserlian, D., Rigal, D., Abello, J. \& Revillard, J. P. (1991). Expression, function and regulation of the intercellular adhesion molecule-1 (ICAM-1) on human intestinal epithelial cell lines. Eur J Immunol 21, 2415-2421.

Kirn, T. J., Jude, B. A. \& Taylor, R. K. (2005). A colonization factor links Vibrio cholerae environmental survival and human infection. Nature 438, 863-866.

Marcatili, A., Cipollaro de l'Ero, G., Galdiero, M., Folgore, A. \& Petrillo, G. (1997). TNF- $\alpha$, IL-1 $\alpha$, IL-6 and ICAM- 1 expression in human keratinocytes stimulated in vitro with Escherichia coli heatshock proteins. Microbiology 143, 45-53.

Martinez-Murcia, A. J., Benlloch, S. \& Collins, M. D. (1992). Phylogenetic interrelationships of members of the genera Aeromonas and Plesiomonas as determined by $16 \mathrm{~S}$ ribosomal DNA sequencing: lack of congruence with results of DNA-DNA hybridizations. Int J Syst Bacteriol 42, 412-421.

Okawa, Y., Ohtomo, Y., Tsugawa, H., Matsuda, Y., Kobayashi, H. \& Tsukamoto, T. (2004). Isolation and characterization of a cytotoxin produced by Plesiomonas shigelloides P-1 strain. FEMS Microbiol Lett 239, 125-130.

Paju, S., Goulhen, F., Asikainen, S., Grenier, D., Mayrand, D. \& Uitto, V. J. (2000). Localization of heat shock proteins in clinical Actinobacillus actinomycetemcomitans strains and their effects on epithelial cell proliferation. FEMS Microbiol Lett 182, 231-235.

Phadnis, S. H., Parlow, M. H., Levy, M., Ilver, D., Caulkins, C. M., Connors, J. B. \& Dunn, B. E. (1996). Surface localization of Helicobacter pylori urease and a heat shock protein homolog requires bacterial autolysis. Infect Immun 64, 905-912.

Retzlaff, C., Yamamoto, Y., Hoffman, P. S., Friedman, H. \& Klein, T. W. (1994). Bacterial heat shock proteins directly induced cytokine mRNA and interleukin-1 secretion in macrophage cultures. Infect Immun 62, 5689-5693.

Saraswathi, B., Agarwal, R. K. \& Sanyal, S. C. (1983). Further studies on enteropathogenicity of Plesiomonas shigelloides. Indian $J$ Med Res 78, 12-18.

Theodoropoulos, C., Wong, T. H., O'Brien, M. \& Stenzel, D. (2001). Plesiomonas shigelloides enters polarized human intestinal Caco-2 cells in an in vitro model system. Infect Immun 69, 2260-2269.

Tsugawa, H., Ono, T., Murakami, H. \& Okawa, Y. (2005). Invasive phenotype and apoptosis induction of Plesiomonas shigelloides $\mathrm{P}-1$ strain to Caco-2 cells. J Appl Microbiol 99, 1435-1443.

Tsukamoto, T., Kinoshita, Y., Shimada, T. \& Sakazaki, R. (1978). Two epidemics of diarrhoeal disease possibly caused by Plesiomonas shigelloides. J Hyg Camb 80, 275-280.

Wang, X. T., Nagaba, Y., Cross, H. S., Wrba, F., Zhang, L. \& Guggino, S. E. (2000). The mRNA of L-type calcium channel elevated in colon cancer. Am J Pathol 157, 1549-1562. 